\title{
PENGEMBANGAN PEMBIBITAN DAN PENGELOLAAN KEBUN KOPI, KARET SERTA SAWIT BERSERTIFIKAT DI DESA KOTANIUR BENGKULU
}

\section{NURSERY DEVELOPING AND MANAGING OF SMALL SCALE COFFEE, RUBBER, AND OIL PALM CERTIFICATED PLANTATIONS IN KOTANIUR BENGKULU}

\author{
Oleh: \\ Priyono Prawito $^{\text {l) }}$, Agus Iswanrijanto ${ }^{1)}$, Sumarto Widiyono ${ }^{2)}$ \\ 1) Prodi Ilmu Tanah Fakultas Pertanian UNIB, \\ ${ }^{2)}$ Fakultas Ilmu Sosial dan Politik UNIB \\ priyono@unib.ac.iddan prawito04@yahoo.com
}

\begin{abstract}
Most of Kota Niur population is farmer, consisting more than $90 \%$ of the population. The three most important of cultivated plants are coffee, rubber, and palm oil, cultivated in traditional system, with relatively low productivity. The purposes of these projects are training the farmers to prepare a good seedling for their plantation, and practicing a good management for their farm. This project has been conducted since May to the December 2013 by establishing 3000 plants of coffee seedling, 11000 plants ofrubber seedling, and 2000 plants of oil palm seedling. Demonstration plots have also been developed for coffee, rubber and oil palm plantations. One-hectare demo plots for coffee, two locations of onehectaredemo plots for rubber, and two locations of one-hectaredemo plots for oil palm plantations. Nursery area of about $1000 \mathrm{~m}^{2}$ has also been established with fence, irrigation, and shading facilities. Training of grafting, occultation, and nursery have also been conducted to prepare for coffee, rubber, and oil palmnursery, resulting in three groups of 5-people well trained in coffee grafting, rubber oculation and oilpalm nursery. Agricultural extension for farm management has also been conducted especially for coffee, rubber, and oil palm plantation management.
\end{abstract}

Keywords: coffee, grafting, occultation, oil palm, rubber

\section{PENDAHULUAN}

Desa Kota Niur adalah salah satu desa di wilayak Kecamatan Taba Penanjung, Kabupaten Bengkulu Tengan. Luas wilayah Desa Kota Niur adalah 525 ha, dengan jumlah penduduk 600 Orang. Mayoritas penduduk adalah petani yang meliputi $91 \%$ penduduk sedang yang lain adalah buruh (tambang dan perkebunan) sebesar $7 \%$ dan sisanya 2\% adalah pedagang. Desa ini berjarak sekitar $30 \mathrm{~km}$ dari pusat kota Bengkulu atau sekitar 40 km dari ibu kota Kabupaten Bengkulu Tengah, dan sekitar 8 km dari jalan lintas Bengkulu Kepahiang (BPS Prop Bengkulu, 2010). Tetapi Desa Kota Niur termasuk salah satu desa di 
wilayah Bengkulu Tengah yang terisolir, karena satu-satu akses ke desa ini hanya dapat ditempuh melalui jalan tambang batubara Bukit Sunur. Tidak ada angkutan umum menuju daerah ini. Transportasi warga desa kota Niur dengan sepeda motor atau menumpang mobil truk perusahaan batubara. Pada saat hari hujan kendaraan bermotor seperti sepeda motor sulit/tidak dapat keluar atau masuk ke Desa Kota Niur (BPS Kab. Benteng. 2010).

Meskipun aksesibilitas Kota Niur sangat terbatas, perkebunan rakyat di desa ini sangat potensial. Hal ini karena wilayah Desa Kota Niur berada pada ketinggian sekitar 150 - $400 \mathrm{~m}$ dari permukaan laut, dengan kondisi tanah relatif subur. Tiga macam perkebunan rakyat yang dominan adalah kopi, karet dan kelapa sawit. Dari segi kesesuaian lahan, ketiga macam jenis komoditi ini cukup sesuai untuk terus di kembangkan di Dasa Koa Niur (Porwanto dkk, 2009).

Luas kebun kopi di desa ini lebih dari 110 ha, dengan kondisi kebun didominasi tanaman muda sekitar $60 \%$, kebun menghasilkan sekitar $20 \%$ dan kebun tua yang telah rusak dan butuh peremajaan seluas sekitar 20\%. Kebun kopi merupakan kebun yang telah lama dikenal masyarakat Desa Kota Niur, yang dikelola dengan cara tradisional. Tanaman kopi dibiarkan tumbuh tinggi tanpa dilakukan pemangkasan. Tumbuhan baru dipangkas ketika sudah tidak produktif, dan dibiarkan tumbuh tunas dan dipelihara seperti sebelumnya begitu seterusnya sampai kopi benar-benar tidak berproduksi lagi, dan kebun ditinggalkan.

Dari hasil wawancara dengan masyarakat diketahui bahwa sebagian dari masyarakat desa ini telah mengenal kopi stekyang memiliki produktivitas lebih tinggi dari pada kebun tradisional. Salah satu petani yang telah menerapkan kopi stek di desa Kota Niur menuturkan bahwa hasil kopi steknya dapat 3-4 kali lipat hasil kopi dari kebun yang dikelola secara tradisional. Informasi senanada juga ditemukan di wilayak Kabupaten Kepahiang dan Kabupaten Rejang Lebong, yaitu di Desa Sumber Urip (Komunikasi Pribadi). Kopi stek yang mereka usahakan rata-rata menghasilkan 3 kali lipat dibanding dengan hasil kopi ketika kebun mereka masih dikelola secara tradisional (bukan kopi stek). Selain hasil lebih tinggi pemeliharaan dan pemanenan kopi stek jauh lebih mudah.

Keadaan kebun Karet masyarakat tidak jauh berbeda dengan kondisi kebun kopi yang ada di daerah ini. Dari hasil wawancara dengan sekretaris desa Kota Niur, pada tahun 2009 terdapat lebih dari 95 ha tanaman karet dengan variasi kebun karet muda, menghasilkan dan kebun rusak. Sekitar 40-an hekter tanaman karet perlu peremajaan. Meskipun berkebun karet telah mereka lakukan secara turun-temurun, inovasi teknologi budidaya karet tidak banyak diterapkan oleh petani. Sebagai contoh penggunaan bibit unggul. Alasan tidak ditanamnya bibit unggul karena harga bibit mahal dan petani tidak dapat membuat bibit sendiri. Berbeda dengan kondisi kebun kopi dan kebun karet, kebun kelapa sawit merupakan komoditi yang relatif baru di Desa Kota Niur. Keragaman umur dan kualitas kebun di desa Kota Niur ini tidak berbeda dengan keberagaman kebun sawit di Kabupaten Bengkulu Tengah pada umumnya, yang mayoritas kebun berupa kebun muda $(60 \%)$ sedang $30 \%$ berupa kebun menghasilkan. Sisanya yang $10 \%$ adalah kebun 
yang rusak tidak terawat atau dibiarkan begitu saja karena kebun tidak menghasilkan. Luas kebun kelapa sawit di desa Kota Niur baru sekitar 60-an ha (Data Potensi Desa, 2009). Namun dalam waktu dua tahun terakhir ini perkembangan perkebunan kelapa sawit rakyat di Desa Kota Niur sangat pesat.

Karena komoditi ini relatif baru maka pengetahuan dan keahlian masyarakat dalam mengelola kebun sawit tidak seterampil mereka mengelola kebun kopi dan kebun karet. Salah satu pengetahuan yang seharusnya mereka ketahui adalah karakter bibit hasil persilangan yang berbeda dengan tanaman kopi dan karet. Apabila mereka terus menanam bibit sawit asalan, mereka tidak akan dapat memperoleh hasil yang baik. Dan hal ini baru akan mereka ketahui setelah tanaman mereka seharusnya mulai panen raya pada tahun 610 tahun.

Untuk itu maka sangat dibutuhkan adanya tranfer knowledge dari para akademisi dan praktisi pekebun kopi, karet dan sawit pada masyarakat Desa Kota Niur khususnya dan Bengkulu Tengah Pada umumnya agar kualitas kebun masyarakat memenuhi standar kebun yang baik yang dapat berproduksi tinggi, meningkatkan pendapatan petani dan pada akhirnya dapat meningkatkan kesejahteraan masyarakat.

Adapun tujuan dari kegiatan ini adalah (1) melatih petani untuk membangun dan mengembangkan kebun bibit kopi, karet dan kelapa sawit yang memenuhi kriteria bibit yang baik; (2) membangun kebun contoh masing-masing komoditi kopi, karet dan kelapa sawit dengan bibit unggul, dan pengelolaan kebun modern; (3) mentransfer pengetahuan tentang pengelolaan kebun kopi, karet dan kelapa sawit menurut cara pengelolaan kebun moderen.

\section{METODE PENGABDIAN}

Pelaksanaan kegiatan ini dikelompokkan ke dalam 5 kelompok kegiatan yaitu (1) Persiapan; (2) Pembuatan kebun pembibitan Kopi, Karet Unggul dan Kelapa sawit; (3) Pembuatan Demplot untuk kebun Kopi, karet, dan Kelapa sawit; (4). Penyuluhan; dan (5) Pemeliharaan kebun (milik masyarakat desa sasaran).

Tahapan persiapan dilakukan sejak memperkenalkan program ini sebelum program disetujui, yaitu dilakukan diskusi dengan beberapa tokoh masyarakat dan petani, untuk menjaring persoalan yang ada dan kemungkinan solusi yang dapat ditawarkan. Kegiatan ini telah dilakukan pada tahun 2011 pada saat proposal akan disusun. Pada saat ini telah dilakukan need assessment di desa Kota Niur, yang salah satu hasilnya adalah prioritas program untuk pengembangan pembibitan dan pembinaan kebun kopi, karet, dan kelapa sawit.

Disadari bahwa tidak akan semua petani menjadi pembibit maka salah satu cara yang ditempuh adalah membina salah satu atau beberapa dari masyarakat/petani Desa Kota Niur untuk menjadi pembibit komoditi kopi, karet dan kelapa sawit. Dengan menggandeng Mitra agar pasca kegiatan (yang didanai Dikti) ini berakhir terus ada pembinaan. 
Pembibitan kopi ditujukan untuk memperoleh bibt kopi unggul denganmelakukan sambung pucuk atau grafting dari kopi batangbawah yang kuat da adaptable di daerah sekitar desa kota Niur. Sumber entres dapat berupa bibit local yang berkualitas baik dan mampu berproduksi tinggi. Selain bibit local juga didatangkan bibit unggul hasil rekayasa Pusat Penelitian Kopi dan Kkakao, Jember yaitu varietas BP 436, BP 534, BP 936, BP 939, yang sudah dikembangkan di Liwa, Lampung Barat, yang berbatasan dengan Bengkulu (Hulupi. 1999; Hulupi dan Mawardi. 1999; Mawardi, 1986).

Berbeda dengan pembuatan bibit kopi, pembibitan Karet akan dilakukan dengan penempelan mata entres dari bibit entres yang bersertifikat, yang didatangkan dari Pusat Penelitian Karet Sembawa, Sumatera Selatan atau dari PTPN 7, dan Dinas Perkebunan Propinsi Bengkulu. Batang bawah dikembangkan dari biji yang juga didatangkan dari daerah Sumatera Selatan, yang diketahui dengan pasti jenis klonnya sehingga dapat dipastikan kompatibilitasnya dengan bahan entressnya. Klon PB-260, yang saat ini merupakan klon yang cocok untuk kondisi iklim di Bengkulu. Klon baru dengan kapasitas produksi dan keunggulan lain seperti IRR 112, IRR 115, dan IRR 118 akan dikembangkan dalam kegiatan ini.

Pembibitan Kelapa sawit meliputi kegiatan prenursery, yaitu menanam kecambah pada polybag kecil ukuran $10 \mathrm{~cm}$. Persemaian diberi naungan untuk mengurangi penyinaran penuh. Tahap nursery adalah tahapan sejak pemindahan bibit yang berumur 3 bulan dari polybag kecil ke polybag ukuran $40 \times 60 \mathrm{~cm}$, bibit tidak perlu naungan, dan jarak bibit diatur $1 \times 1 \mathrm{~m}$. Bibit dipelihara dengan pupuk dan penyiraman sampai umur 11,5 tahun pada saat bibit siap tanam. (Dalimunthe, 2009; Sastrosayono, 2007; Sunarko, 2007).

Untuk menjamin keberlanjutan program ini (karena waktunya sampai 2 tahunan) maka digandeng Mitra untuk mengembangkan pembibitan ini. Mitra I menyediakan lahan, fasilitas pembibitan dan tenaga kerja. Mitra II menjamin keberadaan kecambah sawit bersertifikat, dan menyediakan tempat untuk penyuluhan di lokasi pembibitannya. Sedang Tim Unib bertanggungjawab pada seluruh rangkaian pelaksanaan pembibitan dan penyuluhan dalam kegiatan ini.

Demplot diupayakan berada pada posisi yang strategis, agar mudah di lihat masyarakat kebanyakan, dan berada pada hamparan lahan yang mirip dengan lahan masyarakat pada umumnya, seperti jenis tanah, kelerengan dll. Hal ini untuk menunjukkan secara jujur bahwa lokasi atau lahan seperti yang ada di kawasan pengabdianini dapat dikembangkan seperti yang terlihat di dalam Demplot.

Demplot dikelola mengikuti standar pengelolaan kebun terbaik. Karena demplot memiliki tujuan seperti itu, maka pemilik lahan lokasi demplot adalah petani yang memiliki komitment tinggi dan keterampilan cukup baik dan terbuka untuk maju dalam mengelola kebun. Petani-petani yang bersedia dan terpilihuntuk lokasi demplot adalah Subagio (Mitra I) untuk Kopi stek dari bibit muda, Sdr. Junar untuk kebun Karet unggul, 
Sdr Rudi Untuk kebun Kopi tua yang diremajakan, dan Usman (Sekdes Kota Niur) untuk menjadi pengelola demplot kebun kelapa sawit.

Pada umumnya penyuluhan dilakukan dihadapan masyarakat yang dikumpulkan disuatu tempat dengan mendengarkan ceramah dari penyuluh. Pengalaman ini sudah sangat sering dilakukan baik oleh Tim UNIB sendiri maupun tim lain dalam melakukan penyuluhan. Dari hasil pengamatan selama ini, penyuluhan model ini sangat sedikit keberhasilannya terutama di bidang pertanian. Agar hal ini tidak berulang, dan penyuluhan memperoleh hasil yang lebih baik, yaitu transfer pengetahuan kepada masyarakat dan mengubah perilaku mereka, maka dilakukan dengan metode yang berbeda. Dalam hal-hal tertentu seperti sosialisasi program pertemuan semacam ini masih mungkin dilakukan. Tetapi ketika mulai membahas hal-hal teknis seperti pengelolaan kebun, dan pelatihan pembibitan metode ceramah diganti dengan berdiskusi langsung atau praktek langsung sambil diskusi.

Metode penyuluhan yang dilakukan adalah diskusi, dengan menghadirkan Tim UNIB, Masyarakat, dan satu orang petani yang telah sukses berkebun kopi, karet, dan kelapa sawit. Kebun kopi diwakili Sumardi dari Curup, Kebun karet diwakili Partono dari Bengkulu Utara (ketua Serikat Tani Bengkulu/Petani karet), dan Kebun sawit diwakili Yahyo (Mitra II/pekebun sawit). Fasilitator untuk mengatur jalannya diskusi agar mengarah pada topic atau pokok bahasan diskusi dilakukan oleh Tim UNIB yang talah berpengalaman menjadi fasilitator diskusi para petani. Topikyang menjadi bahasan dalam penyuluhan adalah : (1) Pengelolaan kebun Kopi Stek, (2) Pengelolaan Kebun Karet unggul, dan (3) pengelolaan kebun kelapa sawit bersertifikat.

Pembibitan dipersiapkan pada lokasi Mitra II, karena tersedia lahan yang telah terpagar, terletak dipinggir jalan, dan pengelola masih muda, lulusan D3 Perkebunan, sehingga Mitra II ini diantara anggota masyarakat yang lain relatif memiliki tingkat pendidikan yang lebih baik. Selain letak lahan, tingkat pendidikan, Sdr. Subagio juga telah mencoba menjadi penangkar bibit sawit dan juga karet, sehingga dengan pengabdian ini dapat mempercepat usaha untuk menjadi penangkar bibit agar dapat menyediakan kebutuhan bibit di daerah ini dengan harga yang jauh lebih murah. Karena bibit yang ada berasal dari Kota Bengkulu dan Sekitarnya bahkan dari Seluma sehingga membutuhkan biaya pengangkutan yang tinggi dan bibit menjadi sangat mahal, dan tidak terjangkau olah masyarakat kebanyakan.

Mitra II menyediakan beberapa fasilitas seperti lahan, pagar, pompa air, dan tenaga. Sedang Tim UNIB menyediakan dana untuk membeli biji karet, kopi, dan kecambah kelapa sawit, yang hasilnya pembibitan ini nanti akan digunakan untuk membangun kebun contoh. Mitra I, adalah penangkar bibit Kelapa Sawit bersertifikat, yang merupakan franchise yang memperoleh lesensi dari perusahaan pembenihan milik Negara PPKS Medan. Kontrbusi Mitra I, adalah menyediakan kecambah, memberikan fasilitas berupa tempat pembibitan untuk pelatihan, bahkan dapat membantu atau membimbing Mitra II 
untuk menjadi penangkar benih Sawit bersertifikat, dibawah pengawasan atau dengan lisensi dari Mitra I.

\section{HASIL PENGABDIAN DAN PEMBAHASAN}

\section{Hasil Pengabdian}

Hasil kegiatan pengabdian masyarakat sampai Bulan Desember 2013, secara volume atau fisik telah dicapai sesuai dengan atau sedikit lebih dari rencana. Secara rinci hasil yang dicapai disajikan dalam Tabel 1. Dari table tersebut dapat dilihat bahwa capaian hasil kegiatan pengabdian telah memenuhi target, secara volume. Ada beberapa kegiatan yang harus dilanjutkan seperti pembuatan Demplot, karena bibit yang dihasilkan belum siap tanam. Demikian juga kegiatan penyuluhan yang tidak dapat dilakukan hanya beberapa kali dalam tempo yang singkat.

Tabel 1. Target dan hasil capaian kegiatan pengembangan pembibitan karet, kopi, dan kelapa sawit di Desa Kota Niur Bengkulu tahun 2013

\begin{tabular}{|c|c|c|c|}
\hline No & Target Keluaran & Capaian & Catatan * \\
\hline 1 & $\begin{array}{l}\text { Demplot kebun karet } \\
\text { unggul } 1 \text { lokasi luas } 1 \text { ha }\end{array}$ & $\begin{array}{l}\text { Demplot kebun karet unggul } 2 \\
\text { lokasi luas } 2 \text { ha }\end{array}$ & $\begin{array}{l}\text { Menunggu bibit } \\
\text { siap tanam }\end{array}$ \\
\hline 2 & $\begin{array}{l}\text { Demplot kebun kopi stek } 1 \\
\text { lokasi luas } 1 \text { ha }\end{array}$ & $\begin{array}{l}\text { Demplot kebun kopi stek } 3 \\
\text { lokasi luas } 3 \text { ha }\end{array}$ & $\begin{array}{l}\text { Menunggu bibit } \\
\text { siap tanam }\end{array}$ \\
\hline 3 & $\begin{array}{l}\text { Demplot kebun kelapa } \\
\text { sawit bersertifikat } 1 \text { lokasi } \\
\text { luas } 1 \text { ha }\end{array}$ & $\begin{array}{l}\text { Demplot kebun kelapa sawit } \\
\text { bersertifikat } 2 \text { lokasi luas } 2 \text { ha }\end{array}$ & $\begin{array}{l}\text { Siap ditanam, } \\
\text { bibit telah tersedia } \\
\text { dari Mitra II }\end{array}$ \\
\hline 4 & $\begin{array}{l}\text { Lokasi pembibitan } 1000 \\
\mathrm{~m}^{2}\end{array}$ & $\begin{array}{l}\text { Lokasi pembibitan } 1000 \mathrm{~m}^{2} \\
\text { dengan pagar, pengairan dan } \\
\text { naungan }\end{array}$ & - \\
\hline 5 & Bibit karet 10.000 batang & $\begin{array}{l}\text { Bibit ditanam } 20.000 \text { batang } \\
\text { hidup } 11.000 \text { batang }\end{array}$ & - \\
\hline 6 & Bibit kopi 2000 batang & Bibit kopi 3000 batang & - \\
\hline 7 & Bibit sawit 2000 batang & Bibit sawit 2000 batang & - \\
\hline 8 & $\begin{array}{l}\text { Terlatih dengan baik } 15 \\
\text { petani }\end{array}$ & Terlatih 20 petani (belum mahir) & $\begin{array}{l}\text { Perlu pelatihan } \\
\text { sampai mahir }\end{array}$ \\
\hline 9 & $\begin{array}{l}\text { Terlaksana penyuluhan } \\
\text { pengelolaan kebun }\end{array}$ & $\begin{array}{l}\text { Telah terlaksana penyuluhan } \\
\text { butuh lebih pendalaman }\end{array}$ & $\begin{array}{l}\text { Perlu diskusi } \\
\text { tambahan }\end{array}$ \\
\hline 10 & $\begin{array}{l}\text { Petani menerapkan } \\
\text { hasilpenyuluhan }\end{array}$ & $\begin{array}{l}\text { Penerapan masih pada tahap } \\
\text { sangat awal }\end{array}$ & $\begin{array}{l}\text { Perlu } \\
\text { pendampingan }\end{array}$ \\
\hline
\end{tabular}

* Kegiatan ini akan dilanjutkan bersama-sama antara Mitra khususnya Mitra II dan Dosen UNIB, baik dilakukan secara kelembagaan maupun secara individu. 


\section{Pembahasan}

Beberapa kegiatan dalam pelaksanaan program ini terpaksa dilakukan diluar jadwal yang telah ditentukan dengan beberapa alasan antara lain : ketersediaan bahan seperti biji karet dan kopi hanya tersedia dalam bulan tertentu, pada saat panen. Biji karet tersedia antara bulan April-Mei, dan biji kopi di sekitar lokasi ini tersedia pada bulan Juni-Juli. Selain keberadaan bibit/benih, kondisi cuaca atau lebih tepatnya adalah musim (penghujan dan kemarau) sangat menentukan keberhasilan program pengabdian ini, sehingga kegiatan yang berkaitan dengan musim dimodifikasi sedemikian rupa (ada yang maju dan ada yang mundur) sehingga kegiatan ini tetap dapat berjalan dengan baik. Misalnya pembibitan kelapa sawit yang kecambahnya tersedia setiap saat dapat digeser pada saat masih ada hujan agar penyiraman tidak terlalu berat. Demikian juga waktu yang dibutuhkan untukmenyiapkan bibit untuk demplot adalah bibit yang berumur paling sedikit 12 bulan. Jadi pembibitan kelapa sawit dilakukan awal sebelum kegiatan yang lain dimulai.

Sementara itu pembbitan kopi dan karet tidak dapat dimajukan karena ketersediaan bahan harus menunggu musim panen. Sehingga hal ini akan berbuntut pada mundurnya rangkaian kegiatan yang lain seperti pelatihan pembibitan khususnya okulasi dan grafting, karena harus menunggu bibit yang dikembangkan siap untuk diokulasi yaitu umur paling muda 8 bulan dan umumnya 12 bulan atau menunggu sampai ukuran batang sebesar pensil baru bisa diokulasi. Mundurnya bagian kegiatan ini akan menyebabkan mundurnya pembuatan demplot khususnya tahapan penanaman, karenanbibit belum siap tanam.

Hal lain yang ikut menentukan pergeseran jadwal pelaksanaan adalah tersedianya dana yang tidak pas dengan semua kebutuhan tersebut. Sehingga meskipun sebagian dapat dilakukan di depan dengan menyediakan dana sendiri terlebih dahulu, beberapa bagian kegiatan terpaksa menunggu turunnya dana karena terlalu banyak untuk ditanggulangi dengan dana pribadi. Hal in perlu disampaikan agar dalam mengevaluasi kegiatan semacam ini khususnya yang berkaitan dengan masa panen, umur bibit dan musim, dapat dipertimbangkan dengan obyektif, tidak semata-mata melihat jadwal waktu yang ada di proposal.

\section{Dampak Pengabdian}

Dampak secara nyata tentunya akan terlihat dalam jangka panjang. Dalam waktu dekat ini beberapa dampak pengabdian yang dapat dikemukakan adalah pengetahuan tentang bibit unggul kopi, karet dan sawit. Termasuk bagaimana cara membuat bibit unggul karet dan kopi. Karena mudah pembuatannya, dan mereka telah dapat melakukan sendiri maka mereka tahu bahwa untuk menanam bibit unggul karet dan kopi ternyata tidak semahal yang mereka bayangkan. Sedang untuk bibit sawit bersertifikat, masyarakat memahami bahwa menanam sawit dengan bibit asalan sangat merugikan diri sendiri. Dan mereka memahami betapa pentingnya bibit yang bersertifikat dalam mengembangkan kebun sawit. Namun mereka telah memahami bagaimana menyediakan bibit bersertifikat dengan murah. Dengan pemahaman ini diharapkan petani yang akan membangun kebun 
baru atau meremajakan kebunnya dapat menerapkan pengetahuan dan skil mereka khususnya dalam penyediaan bibit unggul. Sehingga ke depan kebun-kebun yang ada di Desa Kotaniur ini akan menjadi kebun yang mengikuti standard kebun yang baik.

\section{KESIMPULAN DAN SARAN}

\section{Kesimpulan}

Kegiatan pengabdian pada masyarakat ini telah berjalan sesuai dengan tujuan kegiatan untuk Pengembangan pembibitan dan pengelolaan kebun kopi dan karet unggul serta sawit bersertifikat di Desa Kota Niur, Bengkulu Tengah. Meskipun beberapa kendala seperti tidak tepatnya waktu pelaksanaan karena musim, serta keberadaan musim buah untuk tanaman kopi dan karet. Goal kegiatan secara kuantitatif telah terpenuhi atau melampaui target misalnya jumlah bibit, jumlah demplot, jumlah petani yang terlibat dan jumlah pertemuan dalam kegiatan penyuluhan. Secatra rinci hasil capaian dalam kegiatan ini adalah :

1. Telah terbangun (dalam persiapan tanam) demplot kebun karet unggul dikembangkan oleh Junar dan Dadang masing-masing 1 hektar. Persiapan kebun contoh telah dilakukan sejak pemagaran kebun, tebas tebang, dan penganjiran. Sedang pelobangan dan penanaman masih menunggu sampai bibit siap tanam). Demplot kebun kopi stek 3 hektar masing-masing 1 ha atas nama Taryono (kopi stek dengan batang bawah umur 3 tahun), Rudi (kebun kopi stek dengan batang bawah umur lebih dari 15 tahun), dan Subagio (Mitra II) dengan kebun kopi batang bawah umur 1 tahun. Demplot kebun kelapa sawit seluas masing -masing 1 hektar atas nama Usman (sekdes Kota Niur), dan Subagio (Mitra II).

2. Lokasi pembibitan karet telah terbangun dengan fasilitas kebun pembibitan berupa lahan seluas kurang lebih $1000 \mathrm{~m}^{2}$ dengan pagar kawat dan waring, system pengairan, dan kerangka bambu untuk naungan. Juga telah disemaikan sebanyak 3000 bibit kopi untuk batang bawah. Telah tersedia bibit kelapa sawit sebanyak sekitar 1000 batang umur 1 tahun untuk membuat demplot, dan 1000 batang untuk pebibitan awal. Bibit karet sebanyak 11.000 batang dan bibit kopi sebanyak 3000 batang.

3. Telah dilakukan pelatihan pembuatan bibit kopi setek, karet unggul dengan okulasi, dan pembibitan sawit dengan menggunakan bibbit bersertifikat dari PPKS Medan. Sebanyak 20 petani telah mengikuti pelatihan tahap awal.

4. Penyuluhan pengelolaan kebun yang baik juga telah dilakukan, yang diikuti lebih dari 20 orang.

5. Beberapa petani peserta penyuluhan mulai menerapkan hasil-hasil penyuluhan meskipun pada tahapan yang paling mudah dan murah. Tetapi trend menuju ke pengelolaan kebun yang baik telah terlihat, misalnya semangat mereka untuk 
menyediakan batang bawah untuk okulasi ketika akan meremajakan atau membangun kebun karet mereka.

\section{Saran}

Secara kualitatif kegiatan ini masih harus terus dilanjutkan untuk mendampingi agar apa yang telah dihasilkan atau telah dicapai dapat terwujud sebagaimana yang diharapkan dari pelaksanaan program ini.

\section{DAFTAR PUSTAKA}

Badan Pusat Statistik Provinsi Bengkulu, 2010, Bengkulu Dalam Angka, BPS Provinsi Bengkulu.

Badan Pusat Statistik Kabupaten Bengkulu Tengah, 2010, Kabupaten Bengkulu Tengah Dalam Angka, BPS Kabupaten Bengkulu Tengah.

Dalimunthe, M., 2009, Meraup Untung dari Bisnis Waralaba Bibit Kelapa Sawit, Agromedia Pustaka, Jakarta.

Data Potensi Desa, 2009, Monografi Desa Kotaniur, Kabupaten Bengkulu Tengah.

Hulupi, Retno, 1999, Bahan Tanaman Kopi yang Sesuai untuk Kondisi Agroklimat di Indonesia, Warta Pusat Penelitian Kopi dan Kakao, Jember. Vol 15 (I) 64 - 85.

Hulupi, Retno dan Surip Mawardi, 1999, Komposisi Klon-klon Kopi Robusta yang Sesuai untuk Kondisi Iklim Basah, Prosiding Lokakarya dan Ekspose Teknologi Perkebunan. Palembang (II): $169-180$.

Mawardi, Surip, 1986, Memilih Klon-klon Unggul Kopi yang Sesuai untuk Daerah Tertentu, Warta Pusat Penelitian Perkebunan, Jember, No. 3 - 48 hal.

Porwanto, Aldino, T. H., Pardede, A., Arafah, F., Akmal, F., dan Hijriyenti, 2009, Laporan Kelompok KKN Periode 58 Bulan Juli - Agustus 2009 di Desa Kota Niur, Kecamatan Taba Penanjung, Kabupaten Bengkulu Tengah, P3KKN UNIB, (Tidak dipublikasikan).

Sastrosayono, 2007, Budidaya Kelapa Sawit, Agromedia Pustaka, Jakarta.

Sunarko, 2007, Petunjuk Praktis Pengolahan dan Budidaya Kelapa Sawit, Agromedia Pustaka, Jakarta.

\section{UCAPAN TERIMA KASIH}

Dalam kesempatan ini penulis menyampaikan ucapan terimakasih kepada Direktorat Penelitian dan Pengabdian Kepada Masyarakat, Direktorat Jenderal Pendidikan Tinggi, Kementerian Pendidikan Nasional dan Kebudayaan, yang telah mendanai kegiatan ini. Perjanjian pendanaan kegiatan ini sesuai dengan surat Perjanjian Pelaksanaan Penugasan Program Pengabdian kepada Masyarakat Nomor : 28/SP2H/KPM/DIT.LITABMAS/V/ 
2013, tanggal 13 Mei 2013. Kepada LPPM UNIB dan Fakultas Pertanian UNIB penulis ucapkan terima kasih atas kesempatan dan kepercayaan serta fasilitas yang diberikan selama penulis melakukan kegiatan ini. Kepada Masyarakat Kota Niur, penulis ucapkan terimakasih atas perhatian dan keseriusannya mengikuti kegiatan ini. Kepada teman-teman dosen, terimakasih penulis ucapkan atas dorongan baik langsung maupun tidak, sehingga kegiatan ini dapat selesai dengan baik. 